\title{
Challenges and Opportunities for Touring Industry and New Energy Automobile Industry
}

\author{
Jun Yang ${ }^{1 *}$ \\ ${ }^{1}$ University of California, Irvine, USA
}

\begin{abstract}
During pandemic, people's lives are affected dramatically-more than 20 million people have been affected, and most companies have been affected by such virus. However, people may always consider that some industries with inelastic demands such as touring industries and new energy vehicles industries will not be affected by such crisis. By analyzing the data from specific companies, I found the difficulties and opportunities for these industries. For example, touring industry related companies can use several strategies such as promotional strategy and corporate with high-tech companies to tackle with the catastrophe. Besides, electric car industry related companies may set up their technical barriers to boost their sales. From my research, there is no real-inelastic demands for any industries, and the only method for them to survive at any time is always researching new technology and meet customers' demands.
\end{abstract}

\section{Introduction}

During pandemic, everyone is still trying to figure out how and why the coronavirus may appear in the world suddenly. More than 100 million people were infected, and more than 2 million individuals passed away. I would like to discuss about the challenges and opportunities on Touring industry and New Energy Automobile Industry during pandemic. In US, nearly one individual (0.6) has a car, and in Japan, approximately half of them have a car. With the awareness for sustainable development in the world, people may start to consider the possibility to use an alternative energy, which boost the demands for new energy vehicle. In addition, accompanying with the aged tendency of population, population who over 60 years old occupied $17.9 \%$ of the population-249.49 millions have more time to enjoy their lives. Meanwhile, they are more willing to travel around world because of more spare time and high disposable income, which increases the global demand for touring industry.

\section{New energy automobile}

During pandemic, everyone is still trying to figure out how and why the coronavirus may appear in the world suddenly. More than 100 million people were infected, and more than 2 million individuals passed away. People may consider that Covid-19 act as a warming for greedy consumption of limited resources, which incurred the global warming. With the increasingly temperature of the world, the Antarctic Pole started to melt in an incredible speed and amount - the oldest and heaviest ice in the Arctic has declined by stunning $95 \%$. Also, the ozone sphere has been destructed in some ways due to relentless emission of exhaust gas. Besides, although the vaccine of coronavirus appears now, the effectiveness still not been verified by empirical data. In this regard, people start to aware the importance of sustainable development. Meanwhile, gasoline, as a limited resource, has been used dramatically in recent years, and people have become more willing to purchase vehicles, which have inelastic demand, for upgrading their living standards and efficiencies. In US, nearly one individual (0.6) has a car, and in Japan, approximately half of them have a car. With the awareness for sustainable development in the world, people may start to consider the possibility to use an alternative energy. Nowadays, vehicle manufacturing companies initiate to utilize the electricity or hydrogen as the next generation of vehicle for replacing the fuel vehicle. In this way, the electric car is overwhelming in global new energy vehicle market. One of the representative brands of electric car is TESLA.

During pandemic, people are confined to go out. At the same time, for such objective factor, the demand of car dropped. The revenue of many main new energy manufacturing companies has fell dramatically. For example, the first quarter revenue of BYD is lower than that of in 2019 for nearly $35 \%$. At the same time, TESLA catch the demands of electric cars in China due to huge amounts of population and the willingness to promote green energy. According to data from NASA, China contributed nearly $24 \%$ afforest around the world in 10 years, which indicating China's determination to push the afforestation. In order to fulfill the expected future revenue, TESLA has built a factory in China for declining the cost of the car and avoiding the tariff. In this way, a car with decreasing price and same quality may start to attract more customers. For instance, TESLA

$\overline{{ }^{*} \text { Corresponding author: juny19@uci.edu }}$ 
has declined its price nearly $30 \%$ in Mainland of China. In addition, such measure of TESLA not only comply for its own long-term development, but also conform to the national policy of China- "establishment of a "dual circulation" development pattern in which domestic economic cycle plays a leading role while international economic cycle remains its extension and supplement.". Also, someone may start to consider why TESLA does not harness Hydrogen to set up a new energy vehicle. From my perspective, most of the patents of hydrogen car has been controlled by Toyota, and it's costly to make research in a new area. Therefore, from the above reasons, TESLA come to China and chase for more revenues and higher expectations.

The opportunities and challenges for new energy vehicle are as follows.

Every electric vehicle manufacturing companies may try their best to prolong the life of its battery in some ways. Act as a non-biodegradable resource, battery may pollute the Earth environment more than emission of exhaust gas if battery has such a short life for electric car. The average life for battery of electric car is nearly 17 years for $320,000 \mathrm{~km}$, and the companies are still trying to extend it. By doing that, electric car manufacturing companies may become more engaged in environmental protection. The battery life for TESLA has approximately $500,000 \mathrm{~km}$, which is higher than average, and it makes TESLA play a role in environmental protect and has higher chance to gain subsidy from government to do more research and experiments.

The spontaneous combustion for electric vehicle is one of the main worries for people to purchase electric vehicle. As we all know, people will always take safety into consideration when they want to buy a car. TESLA electric car has plenty of spontaneous combustion incident occurred around the world, and it has to commit more funding to fight the danger of spontaneous combustion as the safety problems would always be the first consideration for any consumers.

The charging problems are puzzled for any electric car manufacturing companies. With an innate disadvantage comparing with fuel vehicle, electric car has to spend more time charging. As we all know, people are pursuing for convenience nowadays, and they may have some emergencies to drive a long distance. The charging problems may be taken into consideration for someone always having business trip. On average, the electric car has to cost nearly 8 hours for fully charged, which looks like time-consuming when compare with fuel car. In addition, apart from the time for charging, people may not find the charging piles everywhere, which makes harder for them to charge their cars. In the rural areas, it's hard to find a charging pile. From my perspective, TESLA needs to spend more money on investing charging piles and the speed of charging, while ensuring the safety.

In my opinion, the "ecosystem" for electric devices is quite significant. For example, APPLE has a strong "ecosystem" for all of its devices. iPhone has no such a huge difference comparing with other brands such as Samsung and Huawei. However, if we possess iPhone, iPad, Mac, and Air pods together, these devices will change our daily lives and make our lives easy. Therefore TESLA should invest in auxiliar products for electric cars to build up a proper "ecosystem" to increase customer stickiness.

In my opinion, the "ecosystem" for electric devices is quite significant. For example, APPLE has a strong "ecosystem" for all of its devices. iPhone has no such a huge difference comparing with other brands such as Samsung and Huawei. However, if we possess iPhone, $\mathrm{iPad}$, Mac, and Air pods together, these devices will change our daily lives and make our lives easy. Therefore, TESLA should invest in auxiliar products for electric cars to build up a proper "ecosystem" to increase customer stickiness. For example, TESLA may invest in Phone or wearable devices in the future to set up an ecosystem, which may increase the stickiness of customers and provide better user experience.

In the top cities of China, the government has limited the plate number of fuel car. Sometimes, in order to purchase a fuel car in there, the cost of that car will increase a lot as people have to purchase the plate number for nearly thousands of or even tens of thousand dollars. On the contrary, the plate number for new energy car is free, which will dramatically decline the cost of purchasing car. Due to such policy, people may have more willingness and abilities to purchase electric car, which may boost the demand for TESLA. Also, the tax rate for electric car is lower than that of fuel car in most cities of China, which decreases the cost of the manufacturers. In this way, they are more likely to get an advantage in price to promote their sales. In addition, they can harness the decreased cost to do more research in battery and so on.

The automatic drive is always the core selling points for electric cars. In information age, people may chase for more intelligent and convenient cars than ever before. However, the safety of automatic drive still not been verified yet due to insufficient data and immature devices such as infrared scanner and so on. TESLA should commit more funding to invest in automatic drive to push out such technology into electric car market as there is still no company overcome such difficulty.

\section{Touring industry}

As a country which has second largest GDP-\$14342.9 billion and largest population-1.4 billion people in the world, china has increasingly developed in recent years. China has annually 6\% GDP growth rate before, which is high for such amounts of GDP. Comparing to other developed countries such as US-2\% and Japan-0.5\%, China still has great potential to raise its GDP. Although China has such amounts of population-nearly 1.4 billion people, the discrepancy between GDPs per capita of China-\$8,254.3(2019) and the threshold of becoming developed country- $\$ 12,000-15,000$ is decreasing continuously. With those innate advantages and potentials toward economics, China is reasonable and logical to gain higher expectations in various industries, which may boost the stock market in long run. Some people may consider that some industries with inelastic 
demand may not be affected, but the truth is they are wrong. With the pandemic, nearly half a million people are infected by coronavirus, and the nearly 10,000 people pass away every day, which is a massive loss throughout human history.

Accompanying with the aged tendency of population, population who over 60 years old occupied $17.9 \%$ of the population-249.49 millions have more time to enjoy their lives, and they are more willing to travel around world because of more spare time and high disposable income, which increases the global demand for touring industry. According to such objective factors, people may inadvertently consider that touring industry as a sun industry may have relative high revenue and great expectations, comparing to other sunset businesses such as manufacturing and real estate. However, with the pandemic, such amount of infected people and death rate may trigger long-lasting effects on global economics. For example, although the vaccine is existing now, the validation and sequela of it still not being verified. People may not be confident to take the vaccines and go out or travel around the world. Such psychological state may suppress the speed of economic recovery in short run. Most industries have declined a lot for their revenues, gross margin, and gross profit rate. On the contrary, many people may still think that touring industry may not be influenced by Coronavirus because the tourism acts inelastic for demand. However, due to the financial statement published by public companies, their revenues have dropped dramatically. For example, TCOM only have a half of the revenues- $¥ 13.3$ billion in third quarter of 2020 , comparing to third quarter of 2019- $¥ 27.3$ billion. Also, ABNB has the similar situation with TCOM. The third quarter revenue of 2020 is $\$ 2.5$ billion, comparing to \$3.6billion. Also, due to economic recession, the unemployment rate raised a lot in 2020 globally.

\section{Tactics for touring companies}

Assuming that the price of the plane ticket is elastic, with the drop of price, people may purchase more tickets to travel around during pandemic. Therefore, airline company may prevent the flying with no passengers and increase the revenue. As the costs of the gasoline and plane are sunk costs, with more sold tickets, the airline company may have more profits. For example, during pandemic, Xiamen airline companies decreased the price of the tickets dramatically, normally $\$ 100$ tickets have dropped to nearly $\$ 10$ for increasing occupation rate and revenues. Such discount may raise the revenue of the Xiamen airline company in some ways.

Airline company may make some promotion strategies such as "one ticket for a year". To be more specific, by buying such ticket with a thousand of dollars, passengers could fly in any flights within a year for free. In order to get over the budget crisis, airline company has to recoup funds as soon as possible for preventing the bankruptcy. In addition, as touring intermediary agencies, companies like Xiecheng (TCOM) may issue a VIP ticket for a year flight. In short run, such strategy may help the company get rid of the fiscal crisis by receiving VIP member fees. However, in long run, airline companies may face decline in performance within revenue and gross margin after pandemic. In this strategy, if people believe that the pandemic will affect their life and the economics will be recovered in near future, it's cost-saving for them to purchase such ticket and enjoy these services at cost price as they have frequent flight demands.

The airline companies can take some special travelling plans to satisfy people's needs in travelling. As people have to quarantine 14 days if they travel from one city to another, this strategy meets the psychological demands of people to go sightseeing rather than travel in place. For example, people may travel around the Hongkong in the plane and watch the lightening performance in plane. Such strategy may satisfy people's psychological needs of travelling and also meet the global policies of epidemic prevention and control. In addition, airline company may make some revenues to survive during pandemic to prevent the cut of employees and ensure the employment to some extents.

Incorporate with high-tech companies: on-line travelling, such plan needs touring companies incorporate with high-tech companies like Virtual reality companies. In this way, VR companies have to provide some free devices for touring companies in order to attract people start to do online travelling. By doing this, people may be gratified to do this as it meets their sense of curiosity of VR and travelling. In the information age, by inviting celebrities to participate in and drive this kind of events, the interests of people may be boosted. Besides, the price discrimination should be presented in this strategy. For example, older people and children may have some discounts because they might not interest in such kind of travelling model. Then, touring companies may make some money to make employment and get several revenues. In addition, VR companies may obtain indispensable data for them to continuously upgrade their system and hardware, which paves the way for future development.

Pandemic, act as a challenge and opportunity. With the declining demand for people to travel, companies have enough time to compete with foreign scenic spots. As people may try to gain experiences of foreign lifestyles, cultures, and sceneries, touring companies may somewhat build a resort to meet such demands. Such trend has started in 2018. For example, Disney has set up a resort in Shanghai, which attracts a lot of tourist who were intending to visit the Disney resort of Hongkong or Japan. In this way, people who are not afforded to go abroad may attempt to get such resort having foreign lifestyles and architectural building. Also, people with middle or even higher income level--\$2,000 may be attracted to their if the services are satisfying. In order to raise the quality of service, touring companies may invite foreign expertise to train workers within the resort.

In the top cities of China, the government has limited the plate number of fuel car. Sometimes, in order to purchase a fuel car in there, the cost of that car will increase a lot as people have to purchase the plate 
number for nearly thousands of or even tens of thousand dollars. On the contrary, the plate number for new energy car is free, which will dramatically decline the cost of purchasing car. Due to such policy, the touring industries companies may start to promote a project about the "shared cars". With a lower cost of purchasing the car and sustainable life, the electric car has innate advantages over fuel cars. Such project may further improve the circulation of expenditure within touring industry.

The automatic driving is always an ideal technology for all electric vehicle manufacturing companies. Such technology will facilitate the travelling and make people's life more efficient. In addition, by using such technology well, the traffic accident rate may decrease in some way as the automatic driving will ensure that the car may abide by traffic rules. Therefore, such automatic driving technology is an opportunity for all of vehicle manufacturing companies. The first company overcoming the technical barriers of automatic driving will earn a huge advantage in car market, which may bring enormous amounts of revenues, and such technique could also be used in touring industries to decrease the cost of labor. For example, as the automatic driving becomes mature to some extent, it can also be used in plane, which may dramatically decrease the cost of airline companies in the future.

The touring companies may also invest in touringrelated clothes in order to rise their sales revenue. As we all know, when people travel around world, they may meet extreme weather. Therefore, in order to provide a better user experience for customers, the touring agency could incorporate with several clothing manufacturers to meet cope with such kind of problem. For example, when people want to make a journey to Canada or Iceland in winter, the touring agency may make some recommendations for customers to purchase some cold weather outfit, such as Canada Goose. In this way, the touring companies not only may increase the satisfaction from customers, but it also may increase the commission revenue for touring companies. Such tactic may act as a long-term strategy for touring companies to increase the stickiness of customers.

\section{Conclusion}

During pandemic, people's lives are affected dramatically-more than 20 million people have been affected, and most companies have been affected by such virus. Also, a lot of industries have been affected by coronavirus, especially for touring industry and new energy automobile industry as I have mentioned above. We have presented plenty of difficulties and opportunities for touring industry and new energy vehicle industry during pandemic. We have listed the resolutions for related companies to develop and flourish in the crisis. The inelastic-demand industries will never exist, and the only way for them to survive in the future is that they have to keep researching and setting up technical barriers. For example, during pandemic, touring industries should make promotional strategy and corporate with high-tech companies to explore the market. Also, the new energy vehicle companies should meet customers' demands and resolve the existing problems. Due to the pandemic, each country has its own economic policies. In order to further develop the industries, there are two methods for enterprise: "from top to bottom" and "from bottom to top". As the former, the companies should always follow up the relative policies set up by government. In this regard, they could take the advantages of these policies to develop as they could gain the subsidy or tax exemption. As the latter one, the company could diversify its operation to other fields. For example, a manufacturing company could invest in financial area in some ways if they are optimistic about the future financial market. Overall, we should be hopeful for future global development and prepared to pursue our goals.

\section{References}

1. S. Gössling, D. Scott \& C. Michael Hall, Pandemics, tourism and global change: A rapid assessment of COVID-19, J. Journal of Sustainable Tourism, 29:1, 1-20(2021)

2. Contractor, F.J, The world economy will need even more globalization in the post-pandemic 2021 decade. J. Int Bus Stud (2021)

3. Arribas-Ibar, Manel; Nylund, Petra A.; Brem, Alexander. 2021. "The Risk of Dissolution of Sustainable Innovation Ecosystems in Times of Crisis: The Electric Vehicle during the COVID-19 Pandemic" Sustainability 13, no. 3: 1319.

4. Rutynskyi, Mykhailo and Halyna Kushniruk. "The Impact of Quarantine due to COVID-19 Pandemic on the Tourism Industry in Lviv (Ukraine)." Problems and Perspectives in Management 18, no. 2 (07, 2020): 194-205

5. Masiero, Gilmar, et al. Electric vehicles in China: BYD strategies and government subsidies. J. RAI Revista de Administração e Inovação 13.1 (2016): 311

6. H. Davies, The impact of competitive structure and technological environment on design management: a case study of the UK touring caravan industry. J. Design Studies 14.4 (1993): 365-378

7. S. Boyd, R Butler. Managing ecotourism: An opportunity spectrum approach. J. Tourism Management 17.8: 557-566 (1996)

8. H. Wan et al. Research on new energy automobile manufacturing service derivatization based on TRIZ. J. Sustainability 12.16: 6652(2020)

9. M. He, JS. Zhou, L Ling, A study of supporting legal. policies for improving China's new energy automobile industry based on environmental benefits equilibrium-enlightenment from the environmental subsidies of Germany legal system. J. International Journal of Hydrogen Energy 42.29: 18699-18708 (2017)

10. L. Jiao, PP. Liu, A study on the policy framework of market cultivation in the new energy automobile industry in China. J. 2015 International Conference 
on Logistics, Informatics and Service Sciences (LISS). IEEE, 2015

11. GQ. Fang, New energy automobile industry development commercial mode research. J. Special Zone Economy, 07 (2014)

12. YY Qiu, Analysis of and reflections over the development of new energy automobile and intelligent manufacturing. J. Journal of Physics: Conference Series. 1486. 3. IOP Publishing, 2020

13. S. Volo, O. Giambalvo, Tourism statistics: Methodological imperatives and difficulties: The case of residential tourism in island communities. J. Current Issues in Tourism 11.4 : 369-380(2008)

14. D. Tudorache et al. Difficulties and challenges in applying the european tourism indicators system (ETIS) for sustainable tourist destinations: the case of braşov county in the Romanian carpathians. J. Sustainability 9.10:1879(2017)
15. F. Okumus, O Fevzi, Tourism higher education in Turkey. J. Journal of teaching in travel \& tourism 5.1-2: 89-116(2006)

16. B. Schéou, A. Southon. Ambiguities and difficulties in partnership relations: the case of 'fair tourism' in Western Africa. J. Current issues in tourism, 16.7-8: 753-772 (2013)

17. A. S. Nawar, Insights into the main difficulties of achieving sustainable development of tourism in Iraq. J. Annals of the University of Oradea, Geography Series/Analele Universitatii din Oradea, Seria Geografie, 24.1 : 32-43(2014)

18. Rita, Paulo.Tourism in the European Union. J International Journal of Contemporary Hospitality Management (2000)

19. YF. Lin, PL. Liu, Chinese development strategy and economic convergence. $\mathrm{J}$ Economic Research Journal 3.002 (2003) 